\title{
Sistemas de Alimentação na Produção de Cordeiros para Abate aos 28 kg1
}

\author{
Rafael Batista Medeiros Frescura ${ }^{2}$, Cleber Cassol Pires ${ }^{3}$, Marta Gomes da Rocha ${ }^{3}$, José \\ Henrique Souza da Silva ${ }^{4}$, Liziany Müller ${ }^{5}$
}

\begin{abstract}
RESUMO - Objetivou-se avaliar o desempenho de ovelhas e de cordeiros e as características da carcaça de cordeiros em sistemas de alimentação diferenciados. Foram utilizados 18 cordeiros, distribuídos aleatoriamente com suas mães, 24 horas após o nascimento, em três tratamentos: PCA - pastagem cultivada de azevém (Lolium multiflorum Lam); CON - confinamento sem alimentação privativa aos cordeiros e CCF - confinamento com alimentação privativa para os cordeiros. A pastagem cultivada de azevém foi manejada de forma a não limitar o consumo de matéria seca dos animais em pastejo, com oferta média de forragem de $12 \mathrm{~kg}$ de matéria seca por $100 \mathrm{~kg}$ de peso vivo. No confinamento sem alimentação privativa as matrizes receberam $50 \%$ de silagem de sorgo e $50 \%$ de concentrado ( $11,5 \%$ de proteína bruta (PB) e $64,4 \%$ de nutrientes digestíveis totais (NDT)). No confinamento com alimentação privativa, os cordeiros foram alimentados com $75 \%$ de silagem de sorgo e $25 \%$ de concentrado ( $8,2 \%$ de PB e $60,6 \%$ de NDT) e, ao completarem 21 dias de idade, receberam concentrado (18\% de PB e $72 \%$ de NDT) na quantidade de 3\% do PV. Ganhos médios diários de $300 \mathrm{~g} /$ dia e rendimento de carcaça quente acima de $51 \%$ podem ser obtidos com cordeiros sendo amamentados por suas mães, em pastagem de azevém ou confinamento. Não houve efeito dos sistemas de alimentação em pastagem cultivada de azevém, em confinamento ou em confinamento associado ao creep-feeding, sobre o desempenho e as características da carcaça de cordeiros abatidos aos $28 \mathrm{~kg}$ de peso vivo.
\end{abstract}

Palavras-chave: alimentação privativa, azevém, confinamento, desempenho

\section{Effects of Feeding Systems on Production of Lambs to be Slaughtered at $28 \mathrm{~kg}$}

\begin{abstract}
The objective of this trial was to study the performance of ewes and lambs as well as the characteristics of carcass of lambs in different feeding systems. Eighteen lambs, 24 hours after birth, were randomly assigned with their mothers to one of the following treatments: RP - ryegrass (Lolium multiflorum) pasture; FNCP - feedlot with no creep feeding; and FCP - feedlot with creep feeding. The ryegrass pasture was managed in order to not limit the dry matter intake of the grazing animals with an average supply of $12 \mathrm{~kg}$ of dry matter per $100 \mathrm{~kg}$ of live weight. Animals on FNCP treatment received a diet containing $50 \%$ of sorghum silage $+50 \%$ of concentrate $[11.5 \%$ crude protein (CP) and $64.4 \%$ of total digestible nutrients (TDN). Animals on FCP treatment received a diet containing $50 \%$ of sorghum silage $+25 \%$ of concentrate $(8.2 \%$ CP and $60.6 \%$ TDN) and after they reached 21 days of age were fed an amount of concentrate (18\% CP and $70 \% \mathrm{TDN})$ equal to $3 \%$ of the live weight. Average daily weight gains of $300 \mathrm{~g} /$ day and hot carcass yield greater than $51 \%$ were obtained by nursing lambs on either ryegrass pasture or feedlots. Data from the present trial showed no significant differences among treatments in production and carcass characteristics of lambs slaughtered with $28 \mathrm{~kg}$ of live weight.
\end{abstract}

Key Words: creep feeding, ryegrass, performance, confinement

\section{Introdução}

A produção de carne ovina, em função de sua qualidade, é uma boa alternativa econômica, devendo-se, entretanto, produzir animais que atendam às necessidades de mercado para que a carne tenha uma boa aceitação pelo consumidor (Pires et al., 1999). No Brasil, a carne de ovinos está deixando de ser produzida apenas nas estâncias gaúchas e no sertão nordestino, passando a ser consumida, principalmente, nos grandes centros urbanos. São poucos os criadores nacionais, no entanto, que se preocupam em produzir ovinos jovens (cordeiros), com bom acabamento de carcaça (Macedo et al., 2000).

Na produção de cordeiros para abate, é necessário manejo alimentar adequado que permita rápida terminação do cordeiro e a obtenção de carcaças com características adequadas ao consumo. Não existe finalidade em antecipar o desmame quando as condições ambientais propiciam engorda ao pé da mãe, com alto desempenho, salvo se o leite é requerido para outros propósitos (Brown, 1994). A produção intensiva

\footnotetext{
${ }^{1}$ Parte da Dissertação de Mestrado do primeiro autor.

2 Zootecnista, M.Sc. Bolsista CAPES (rfrescura@bol.com.br).

${ }^{3}$ Med. Vet., Dr., Professor Titular DZ-UFSM, CEP: 97105-900, Santa Maria, RS (cpires@.ccr.ufsm.br).

4 Eng. Agr., Phd., Professor Adjunto DZ- UFSM, Santa Maria, RS.

5 Aluno de graduação em Zootecnia.
} 
de cordeiros poderia ser uma alternativa de negócios para os produtores incrementarem a renda da propriedade, visto que pode-se abater estes animais de três a quatro meses de idade (Muniz et al., 1997).

O sistema de produção de carne ovina em pastagem visa o aumento do peso dos animais e a redução na idade de abate e, conseqüentemente, a obtenção de carcaças de melhor qualidade, tornando esta prática viável nos sistemas de produção do Rio Grande do Sul (Canto et al., 1999; Tonetto et al., 2004). A utilização de forrageiras como fonte primária de energia na dieta de ruminantes apresenta grandes vantagens econômicas para o desenvolvimento da ovinocultura, entretanto, são necessários a escolha correta da forrageira, o conhecimento do quanto a forragem atende as exigências dos animais, o manejo das pastagens e a conservação de alimentos para períodos de escassez (Silva Sobrinho, 2001).

Segundo Siqueira et al. (1993), o confinamento de cordeiros é uma importante alternativa, pois o oferecimento do alimento no cocho evita a presença de altas cargas parasitárias na pastagem. Esses autores, ao compararem diferentes pesos de abate de cordeiros, qualidade da carcaça e renda líquida por cordeiro, concluíram que, economicamente, o peso de abate de $28 \mathrm{~kg}$ é o mais adequado.

A alimentação dos cordeiros a partir dos primeiros dias de vida no sistema de creep feeding repre- senta alternativa prioritária e estratégica na produção de cordeiros, devendo ser iniciada logo após o nascimento, para adaptar os animais ao consumo de alimento sólido (Neres et al., 2001a).

Objetivou-se, com este trabalho, avaliar o desempenho de ovelhas e de cordeiros e as características da carcaça dos cordeiros terminados em pastagem cultivada de azevém (Lolium multiflorum Lam.) ou em confinamento.

\section{Material e Métodos}

O trabalho foi realizado no período de julho a novembro de 2001. Os dados meteorológicos durante o período experimental foram coletados na estação meteorológica do Departamento de Fitotecnia da Universidade Federal de Santa Maria e encontram-se na Tabela 1.

Foram utilizados 18 cordeiros não-castrados, cruzas Ile de France x Texel, de partos simples, distribuídos aleatoriamente com suas respectivas mães, nos tratamentos: PCA- Pastagem cultivada de azevém (Lolium multiflorum Lam); CON-Confinamento sem alimentação privativa para os cordeiros e CCFConfinamento com alimentação privativa para os cordeiros. A alimentação privativa foi fornecida em um sistema de creep-feeding. Em todos os tratamentos, os cordeiros e suas mães permaneceram juntos

Tabela 1 - Dados meteorológicos de temperatura, precipitação pluviométrica e umidade relativa do ar (URA) referentes ao período experimental (julho/novembro 2001)

Table 1 - Meteorological data temperature, amount of rainfall and relative air humidity (RAH) of the experimental period (july/ november 2001)

\begin{tabular}{|c|c|c|c|c|c|}
\hline \multirow[t]{2}{*}{$\begin{array}{l}\text { Mês } \\
\text { Month }\end{array}$} & \multicolumn{3}{|c|}{$\begin{array}{l}\text { Temperatura }\left({ }^{\circ} \mathrm{C}\right) \\
\text { Temperature }\left({ }^{\circ} \mathrm{C}\right)\end{array}$} & \multirow{2}{*}{$\begin{array}{c}\text { Precipitação } \\
\text { Rainfall } \\
\text { (mm) }\end{array}$} & \multirow{2}{*}{$\begin{array}{r}\text { URA } \\
\text { RAH } \\
(\%)\end{array}$} \\
\hline & $\begin{array}{l}\text { Média } \\
\text { Average }\end{array}$ & $\begin{array}{l}\text { Máxima } \\
\text { Maximum }\end{array}$ & $\begin{array}{l}\text { Mínimo } \\
\text { Minimum }\end{array}$ & & \\
\hline $\begin{array}{l}\text { Julho } \\
\text { July }\end{array}$ & 13,8 & 31,6 & 0,0 & 201,5 & 82,0 \\
\hline $\begin{array}{l}\text { Agosto } \\
\text { August }\end{array}$ & 18,0 & 32,0 & 6,6 & 68,5 & 76,0 \\
\hline $\begin{array}{l}\text { Setembro } \\
\text { September }\end{array}$ & 17,1 & 28,8 & 3,8 & 237,1 & 81,0 \\
\hline $\begin{array}{l}\text { Outubro } \\
\text { October }\end{array}$ & 20,7 & 36,2 & 8,3 & 165,2 & 76,0 \\
\hline $\begin{array}{l}\text { Novembro } \\
\text { November }\end{array}$ & 21,7 & 35,8 & 12,2 & 108,0 & 73,0 \\
\hline $\begin{array}{l}\text { Médias } \\
\text { Average }\end{array}$ & 18,3 & 32,8 & 6,1 & 156,0 & 77,6 \\
\hline
\end{tabular}


até o abate, constituindo o que foi caracterizado unidade ovina (ovelha + cordeiro).

A área total da pastagem cultivada de azevém $(L$. multiflorum) foi de 1,07 ha, subdividida em duas áreas menores. A pastagem foi estabelecida no mês de maio/ 2001 , com $50 \mathrm{~kg} /$ ha de semente de azevém, adubação de base de $200 \mathrm{~kg} / \mathrm{ha}$ de NPK (05-20-20) e adubação nitrogenada de $157,70 \mathrm{~kg} /$ ha de nitrogênio, dividida em quatro aplicações. As avaliações da massa de forragem da pastagem cultivada foram realizadas pelo método de dupla amostragem, conforme Gardner (1986), a cada 21 dias. A massa de forragem pretendida foi de 1.000 a $1.200 \mathrm{~kg} / \mathrm{ha}$ de MS, para que não houvesse limitação ao consumo dos animais em pastejo.

No dia correspondente à metade do intervalo entre duas avaliações, a forragem aparentemente consumida pelos animais foi coletada por dois avaliadores, utilizando-se a técnica de simulação de pastejo (Gibb \& Treacher, 1976). O sistema de pastejo adotado foi o contínuo com lotação variável. Foi realizada a estimativa da taxa de acúmulo de matéria seca empregando-se gaiolas de exclusão e, para o cálculo da taxa de acúmulo diário, foi utilizada a equação descrita por Campbell (1966). A oferta de forragem (OF; $\mathrm{kg}$ de $\mathrm{MS} / 100 \mathrm{~kg}$ de PV) foi calculada pela equação $\mathrm{OF}=(\mathrm{MF} / 28+\mathrm{TAD}) / \mathrm{CA}$, em que: MF é a massa de forragem; 28, o número de dias do período experimental; TAD, a taxa diária de acúmulo de matéria seca; e CA, a carga animal média. As perdas de forragem foram avaliadas a cada 21 dias. Em cada piquete, foram marcados 15 pontos com estacas e, nestes pontos, dentro da área delimitada por um quadrado de $0,1 \mathrm{~m}^{2}$, foram coletados os materiais senescente, morto e danificado pelo pisoteio e pastejo. Após cada coleta, as amostras foram secas em estufa e pesadas para cálculo da perda de forragem por hectare.

Para o cálculo da estimativa do consumo de MS, foi subtraída da produção total de MS/ha (massa de forragem inicial + (taxa de acúmulo diário * número de dias)) a forragem disponível no final do período experimental e as perdas de forragem ocorridas ao longo do período de pastejo. Dividindo o consumo estimado de MS/ha pela carga animal média, obteve-se o consumo estimado de MS em \% do PV. O período de utilização da pastagem foi de 09/07 a 1/11/2001.

Nos confinamentos a céu aberto, o piso era de terra, coberto com casca de arroz, com área disponí- vel de $10 \mathrm{~m}^{2} /$ ovelha+cordeiro, onde a silagem de sorgo (AG 2002) e o concentrado eram fornecidos à vontade, às 8 e 16h. A quantidade oferecida foi ajustada diariamente, aumentando ou diminuindo em $10 \%$, conforme a sobra do dia anterior, que deveria ser de até $20 \%$ da quantidade fornecida. Foi utilizada mistura mineral com livre acesso em cada tratamento. O concentrado utilizado na alimentação dos animais em confinamento foi fornecido pela Santista Alimentos. No confinamento sem alimentação privativa para os cordeiros $(\mathrm{CON})$, a alimentação consistiu de $50 \%$ de volumoso e $50 \%$ de concentrado $-11,5 \%$ de PB e $64,40 \%$ de NDT, com consumo de $11,34 \%$ de PB e $64,28 \%$ de NDT por unidade ovina.

No confinamento com alimentação privativa (CCF), utilizou-se $75 \%$ de volumoso e $25 \%$ de concentrado, em dieta contendo $8,20 \%$ de PB e $60,60 \%$ de NDT, de modo que o consumo por unidade ovina foi de $7,80 \%$ de PB e $60,48 \%$ de NDT. A diferença entre a dieta oferecida e o consumo dos animais é decorrente da variação da PB e do NDT verificada tanto na silagem como no concentrado. Quando os cordeiros atingiram 21 dias no tratamento, começaram a receber o concentrado em quantidade de $3 \%$ do peso vivo $(8,12 \%$ de PB e $72,01 \%$ de NDT) e o consumo médio, durante três períodos de 21 dias, foi de $1,90 \%$ do PV. Os animais foram dosificados com vermífugo, para o controle de endoparasitos no início do experimento e a cada 30 dias.

Ovelhas e cordeiros foram pesados no início do experimento e a cada 21 dias com prévio jejum de sólidos e líquidos de 14 horas. Foram coletadas amostras dos alimentos oferecidos e das sobras nos tratamentos para realização de análises bromatológicas.

Foram determinados os teores de matéria seca, matéria orgânica, proteína bruta, extrato etéreo, fibra bruta, extrativos não-nitrogenados e cinzas, pelas técnicas descritas no AOAC (1984) e a digestibilidade in vitro da matéria orgânica e da matéria seca (Tilley \& Terry, 1963).

Para obtenção da concentração de NDT, utilizouse o cálculo: $\mathrm{MO}=100-\mathrm{MM}$; em que: $\mathrm{MO}=$ matéria orgânica; $\mathrm{MM}=$ materia mineral; \%NDT $=(\mathrm{MO} x$ DIVMO)/100; DIVMO = digestibilidade in vitro da matéria orgânica (Freitas et al., 1994).

Os parâmetros avaliados nas ovelhas foram: peso no início do experimento, peso das ovelhas no abate dos cordeiros e ganho médio diário. Nos cordeiros: 
peso no início do experimento, peso de abate, ganho médio diário e dias do cordeiro no experimento para atingir o peso de abate. Após o abate dos cordeiros, foram obtidos o peso e o rendimento da carcaça quente. Após 24 horas de resfriamento da carcaça, a $2^{\circ} \mathrm{C}$, foram obtidos o peso e o rendimento de carcaça fria e o índice de quebra ao resfriamento. A área de olho de lombo foi obtida pela exposição do músculo Longíssimus dorsi após um corte transversal na carcaça, entre a $12^{\mathrm{a}}$ e $13^{\mathrm{a}}$ costelas, traçando o seu contorno em papel vegetal (Müller, 1980). Para determinação e registro da área, foi utilizado o programa SITER 3.1 modelo A2 descrito por Giotto (2001). Nesta seção, foram avaliados, por meio de uma escala de pontuação (Müller, 1980), a espessura da gordura de cobertura e o marmoreio $(1,0=$ não existente até $5,0=$ existente) .

$\mathrm{Na}$ metade esquerda da carcaça, foi medido o comprimento (distância entre o bordo anterior da sínfise ísquio-pubiana e o bordo anterior da primeira costela no seu ponto médio); comprimento de perna (distância entre o bordo anterior da sínfise ísquiopubiana e a porção média dos ossos do tarso); profundidade de peito (distância máxima entre o dorso e o externo); espessura de coxão (distância entre os bordos interno e externo da parte superior da perna em sua parte mais larga) e gordura de cobertura $(1,0=$ excessivamente magra até $5,0=$ excessivamente gorda). Também foi mensurada a compacidade da carcaça (peso de carcaça fria/comprimento interno da carcaça). Estas avaliações seguiram a técnica descrita por Osório et al. (1998).

O delineamento experimental adotado foi o inteiramente casualizado com três tratamentos. A metodologia estatística incluiu a análise de variância e o teste F. Diferenças significativas a 5\% ensejaram aplicação do teste Tukey no mesmo nível de significância. Foram feitos estudos de regressão do ganho médio diário em relação à duração (em dias) do experimento. As análises foram realizadas pelo pacote estatístico SAS (1993).

\section{Resultados e Discussão}

Os percentuais de matéria seca, matéria mineral, digestibilidade in vitro da matéria seca, digestibilidade in vitro da matéria orgânica, nutrientes digestíveis totais e proteína bruta da silagem de sorgo, do concentrado e da forragem aparentemente consumida na pastagem de azevém são apresentados na Tabela 2 .

O teor de MS da silagem na colheita é um parâmetro que ajuda a definir a manutenção da qualidade e a estabilidade do processo fermentativo do material ensilado (Neumann et al., 2002). Borges et al. (1997) consideram o teor ideal de MS de 30 a $35 \%$ e, portanto, o teor de MS de 27,8\% na silagem encontrado neste trabalho é considerado baixo, não favorecendo o desenvolvimento de fermentações láticas.

A DIVMS do híbrido de sorgo utilizado neste experimento $(59,18 \%)$ foi superior, provavelmente em função da maior proporção de panícula na massa ensilada, aos valores de 43,25 e 51,45\%, relatados por Tonetto et al. (2004) e Neumann et al. (2002), respectivamente, na mesma variedade de sorgo. $\mathrm{O}$ valor de NDT de $56,80 \%$, no entanto, é ainda inferior ao valor de $60 \%$, característico de silagens de sorgo com baixo percentual de grãos (NRC, 1989). O teor de PB de $4,88 \%$ é inferior ao relatado por Tonetto et al. (2004) e Neumann et al. (2002), de 6,54 e 5,94\%, respectivamente, e pode estar relacionado à perda de nutrientes por lixiviação, resultante do baixo teor de matéria seca da massa ensilada.

Tabela 2 - Percentuais de matéria seca (MS), matéria mineral (MM), digestibilidade in vitro da matéria seca (DIVMS) e da matéria orgânica (DIVMO), nutrientes digestíveis totais (NDT) e proteína bruta (PB) da silagem de sorgo (SS), do concentrado (CC) e da forragem aparentemente consumida na pastagem cultivada (FCPC)

Table 2 - Percentages of dry matter (DM), mineral matter (MM), in vitro digestibility of dry matter (IVDDM) and of organic matter (IDMO), total digestible nutrients (TDN) and crude protein (CP) of sorghum silage (SS), concentrate (CC) and hand puckling forage of ryegrass pasture (HDFRP)

\begin{tabular}{llccccc}
\hline Componente da dieta & MS & MM & DIVMS & DIVMO & NDT & PB \\
Diet component & $D M$ & $M M$ & $I V D D M$ & IVDMO & $5 P$ & 4,88 \\
\hline SS $(S S)$ & 27,8 & 5,07 & 59,2 & 59,85 & 56,80 & 72,01 \\
CC $(C C)$ & 88,2 & 9,80 & 80,2 & 79,84 & 64,12 \\
FCPC $($ HPFRP) & 20,6 & 12,10 & 72,9 & 73,26 & 64,38 & 20,60 \\
\hline
\end{tabular}


No período experimental, o valor médio da massa de forragem foi de $965,7 \mathrm{~kg} / \mathrm{ha}$ de MS e a oferta de forragem (OF) foi de 12,14 $\mathrm{kg}$ de MS/100 kg de PV, valor considerado como não-limitante ao consumo animal. Em gramíneas temperadas, para que não haja limitação do consumo, a OF deve ser, no mínimo, três vezes o valor do consumo estimado para o animal (Gibb \& Treacher, 1976). Segundo o NRC (1985), o consumo estimado para ovelhas de $60 \mathrm{~kg}$ amamentando um cordeiro, nas primeiras 6 a 8 semanas, é de $2,3 \mathrm{~kg}$ de MS e, portanto, a OF não restringiu o consumo, que foi 3,6 vezes superior ao valor estimado.

Os valores médios de taxa de acúmulo diário de MS e carga animal foram, respectivamente, de 52,02 $\mathrm{kg} / \mathrm{ha}$ de MS/dia e 795,24 kg/ha de PV. O valor da carga equivale a 11,5 unidades ovinas/hectare. A média de peso da unidade ovina (ovelha + cordeiro) foi de 69,37 kg. Estes valores se assemelham aos valores médios observados por outros autores no mesmo local (Tonetto et al., 2004; Farinatti, 2002).

O manejo da pastagem, proporcionando oferta de forragem adequada, permitiu que os ovinos em pastejo selecionassem forragem de alta qualidade, provavelmente constituída sobretudo por folhas, com percentual de proteína bruta (PB) de 20,6\% e digestibilidade in vitro da matéria orgânica (DIVMO) de

$73,26 \%$

(Tabela 2). Estes valores, superiores aos encontrados para silagem de sorgo, quando somados ao consumo adequado de matéria seca, são determinantes para um desempenho individual satisfatório.

Os valores médios para consumos de matéria seca ( $\mathrm{kg}$ por unidade ovina ou \% PV da unidade ovina), de nutrientes digestíveis totais (CNDT) e de proteína bruta (CPB) são apresentados na Tabela 3 .

O consumo estimado de MS em porcentagem de peso vivo para o tratamento PCA foi de 5,31\%, bem próximo ao relatado por Farinatti (2002), de 5,38\% do PV, em trabalho com cordeiras ao pé da mãe em pastagem de azevém com carga média de 846,14 kg/ha de PV.

Ovelhas de $60 \mathrm{~kg}$ amamentando cordeiro de parto simples nas primeiras 6 a 8 semanas, devem consumir diariamente de 2,3 $\mathrm{kg}$ de MS, 1,50 kg de NDT e $0,319 \mathrm{~kg}$ de $\mathrm{PB}$ (NRC, 1985). Os valores de consumo/ $\mathrm{kg}$ da unidade ovina verificados para o tratamento PCA estão acima das exigências diárias preconizadas pelo NRC (1985) para as ovelhas (Tabela 3). O método utilizado para estimar o consumo, pelo desaparecimento de forragem, poderia estar superestimando este consumo. Para ovelhas do tratamento $\mathrm{CON}$, os valores foram aproximados, enquanto, em $\mathrm{CCF}$, os valores de consumo de matéria seca estiveram aquém das exigências diárias recomendadas. Em PCA e CON o consumo dos cordeiros não foi computado.

Valores dos pesos das ovelhas no início do experimento, no momento do abate dos cordeiros e o ganho médio diário das mesmas, nos diferentes tratamentos, encontram-se na Tabela 4

Tabela 3 - Médias de consumos de matéria seca (CMS), em kg por unidade ovina e em porcentagem do peso vivo (CMS, \%PV), de nutrientes digestíveis totais (CNDT) e de proteína bruta (CPB), em pastagem cultivada de azevém (PCA), em confinamentos sem alimentação privativa (CON) e com alimentação privativa (CCF)

Table 3 - Means intakes of dry matter intake (DMI), expressed as amount (kg) or as \% of live weight, kg per sheep unit, dry matter intake in \% of live weight (DMI,\%), total digestible nutrients (TDN) and crude protein (CPI) in ryegrass pasture - RP, confinement - FNCP and confinement with creep-feeding - FCP

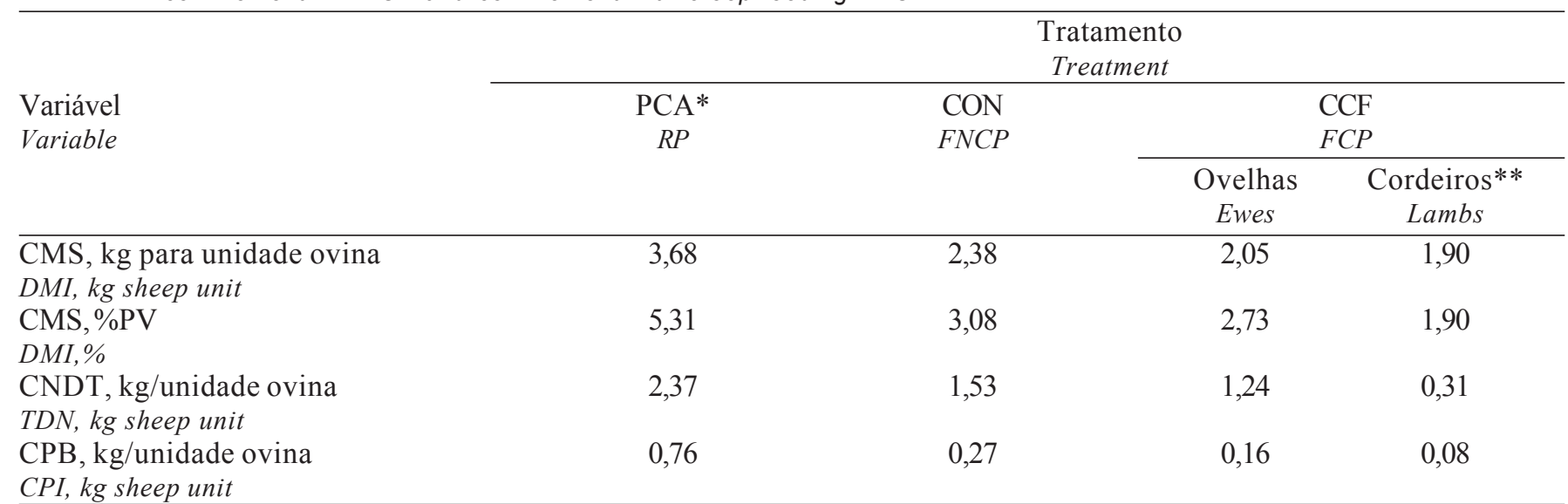

** Consumo dos cordeiros no creep feeding (Lamb intake in creep feeding).

* Valores estimados (Estimated values). 
Verifica-se que o peso das ovelhas no momento do abate dos cordeiros foi superior para o tratamento CON $(66,43 \mathrm{~kg})$, quando comparado ao tratamento PCA $(50,95 \mathrm{~kg})$. O tratamento CCF, por sua vez, não diferiu dos demais tratamentos, apesar de o peso final das ovelhas ser $15,69 \%$ superior ao peso final das ovelhas do tratamento PCA e $12,72 \%$ inferior ao das ovelhas do tratamento $\mathrm{CON}$. O maior consumo de MS, NDT e PB/kg por unidade ovina (Tabela 3) não refletiu no GMD das ovelhas do tratamento PCA, que foi inferior ao GMD das ovelhas do tratamento $\mathrm{CON}$ e semelhante ao GMD no CCF. É importante ressaltar que os valores de consumo dos animais do tratamento PCA são estimados.

De acordo com os ganhos de pesos médios diários (Tabela 3), o que pode ter prejudicado o desempenho das ovelhas do tratamento PCA foi o fato de antes serem encaminhadas ao seu respectivo potreiro, foram utilizadas outras ovelhas para se adequar a massa de forragem, que foram computadas na estimativa de consumo. Este manejo pode ter aumentado o grau de infestação da pastagem por vermes que podem ter prejudicado o desempenho das ovelhas deste tratamento.

Valor de GMD superior ao encontrado neste experimento para as ovelhas em PCA foi relatado por Müller et al. (2002), que trabalharam com cordeiros não-castrados ao pé da mãe, em pastagem de azevém, utilizando carga média de $744 \mathrm{~kg}$ de peso vivo/ha e oferta de 9,16 kg de MS/100 kg de peso vivo e verificaram GMD de $0,081 \mathrm{~kg}$.

As ovelhas do tratamento $\mathrm{CON}$ apresentaram desempenho superior $(\mathrm{P}<0,05)$ às ovelhas do trata- mento PCA. O desempenho das ovelhas do tratamento CCF não diferiu das ovelhas do tratamento PCA e CON, apesar de o GMD do tratamento CON ter sido 365 e 128\% superior ao GMD do PCA e CCF, respectivamente.

Os valores de GMD das ovelhas dos tratamentos $\mathrm{CON}$ e CCF foram superiores aos relatados por Müller et al. (2002), que trabalharam com pastagem natural suplementada e confinamento (silagem de sorgo + concentrado) e observaram ganho médio diário de $0,068 \mathrm{~kg}$ e $-0,120 \mathrm{~kg}$, respectivamente. Esta diferença de GMD ocorreu porque, no trabalho supracitado, o concentrado foi oferecido aos animais na proporção de $1,3 \%$ do peso vivo do conjunto ovelha mais cordeiro até 42 dias do experimento. Após, as ovelhas receberam 0,5\% do PV até o abate dos cordeiros, mas houve restrição do concentrado, o que limitou o GMD destas ovelhas em relação ao presente experimento.

Os valores referentes ao peso no início do experimento, ao peso de abate, ao ganho médio diário e aos dias do cordeiro no experimento para atingir o peso de abate, nos diferentes tratamentos, estão apresentados na Tabela 5.

O ganho médio diário não foi influenciado pelo manejo alimentar, apesar de os cordeiros do tratamento CON terem GMD 16,49\% superior ao dos cordeiros CCF, podendo esta diferença estar associada à melhor condição alimentar oferecida às ovelhas mães dos cordeiros do tratamento $\mathrm{CON}$, em que o consumo foi de $11,34 \%$ de PB e $64,40 \%$ de NDT (Tabela 2). Por outro lado, o consumo das ovelhas do CCF foi de $7,80 \%$ de PB e $60,48 \%$ de NDT.

Tabela 4 - Valores médios dos pesos das ovelhas no início do experimento (POIE), no momento do abate dos cordeiros $(P O A B)$ e do ganho médio diário das ovelhas (GMD), coeficiente de variação (CV), valor de $F(F)$, e probabilidade $(\mathrm{Pr}>\mathrm{F})$ nos tratamentos de pastagem cultivada de azevém (PCA), de confinamentos sem alimentação privativa (CON) e com alimentação privativa (CCF)

Table 4 - Average values of ewes weight at the beginning of the experiment (WSBE), at slaughter day (WSS) of lambs and daily weight gain (DWG) of sheep, coefficient of variation (CV), $F$ value and probability $(P r>F)$ in ryegrass pasture - RP, confinement - FNCP and confinement with creep-feeding - FCP

\begin{tabular}{|c|c|c|c|c|c|c|}
\hline \multirow{3}{*}{$\begin{array}{l}\text { Variável } \\
\text { Variable }\end{array}$} & \multicolumn{3}{|c|}{ Tratamento (Treatment) } & \multirow[b]{2}{*}{$\mathrm{CV}$} & \multirow[b]{2}{*}{ F } & \multirow[b]{2}{*}{$\operatorname{Pr}>\mathrm{F}$} \\
\hline & PCA & $\mathrm{CON}$ & $\mathrm{CCF}$ & & & \\
\hline & $R P$ & $F N C P$ & $F C P$ & $\mathrm{CV}$ & $F$ & $P r>F$ \\
\hline POIE (kg) & 49,083 & 58,083 & 54,667 & 17,35 & 1,54 & 0,247 \\
\hline $\begin{array}{l}W S B E(k g) \\
\text { POAB }(\mathrm{kg}) \\
W S S(k g)\end{array}$ & $50,950^{\mathrm{b}}$ & $66,433^{\mathrm{a}}$ & $58,933^{\text {ba }}$ & 16,35 & 3,89 & 0,043 \\
\hline $\begin{array}{l}\operatorname{GMD}(\mathrm{kg}) \\
D W G(\mathrm{~kg})\end{array}$ & $0,026^{\mathrm{b}}$ & $0,121^{\mathrm{a}}$ & $0,053^{\text {ba }}$ & 15,17 & 4,67 & 0,026 \\
\hline
\end{tabular}

Médias seguidas de letras distintas na linha diferem $(P<0,05)$ entre si pelo teste Tukey.

Means followed by different letters in the row differ $(P<0.05)$ by Tukey test. 
O número de dias necessários para os cordeiros atingirem o peso de abate não sofreu influência do manejo alimentar, apesar de aqueles do tratamento CON terem gasto, em média, cinco e nove dias a menos que os animais dos tratamentos PCA e CCF, respectivamente, para alcançarem o peso de abate pré-estabelecido.

Tonetto et al. (2004) trabalharam com cordeiros não-castrados e verificaram GMD de $0,325 \mathrm{~kg}$ e 76 dias ao abate, em pastagem natural suplementada com acesso à alimentação privativa, enquanto, em pastagem de azevém, obtiveram GMD de 0,404 kg e 62 dias ao abate, e, em confinamento, GMD de $0,213 \mathrm{~kg}$ e 98 dias ao abate. Neste trabalho, os resultados obtidos em confinamento de chão batido, a céu aberto, indicam a possibilidade de a utilização deste sistema em condições ambientais do Rio Grande do Sul, pois permitiu que os animais tivessem bom desempenho, sem a necessidade de grandes investimentos em instalações.

Siqueira et al. (1993) ressaltam que a terminação em confinamento envolve investimentos adicionais, sobretudo em instalações e alimentação. A adoção de confinamento para terminação de cordeiros pode ser vista como uma alternativa para aumentar a taxa de lotação da propriedade, pois propicia liberação de área para outras categorias, como para recria das borregas, possibilitando melhores condições alimentares, além de beneficiar diretamente as matrizes, que são confinadas juntamente com seus cordeiros e, portanto, em melhores condições nutricionais até o encarneiramento, o que pode proporcionar até três partos em dois anos.
A relação do ganho médio diário em função do tempo (dias) nos tratamentos pastagem de azevém e confinamento é apresentada na Figura 1.

Nos tratamentos PCA e CON, houve queda do ganho de peso dos cordeiros de 0,002 e $0,003 \mathrm{~kg}$, respectivamente, para cada dia do experimento. A redução do ganho de peso à medida que o cordeiro tem sua idade avançada pode estar relacionada à mudança do hábito alimentar, posto que, no inicio do confinamento, estes animais se alimentam quase que exclusivamente de leite. Portanto, nos tratamentos PCA e CON, a queda no ganho médio diário do cordeiro provavelmente acompanhou a curva de lactação das ovelhas. Segundo Figueiró (1989), no período de aleitamento, o cordeiro apresenta alta eficiência alimentar, pois com apenas $10 \%$ do tempo necessário, ganha $37,5 \%$ do peso adulto. $\mathrm{O}$ autor observou que, a partir de seis a oito semanas de lactação, a ovelha tem sua produção de leite reduzida, com queda de 40 a 50\% do valor do início da lactação.

Os pesos de carcaças quente e fria, os índices de quebra ao resfriamento, o rendimento de carcaças quente e fria em cada tratamento encontram-se na Tabela 6 .

Os pesos de carcaças quente e o peso de carcaça fria foram semelhantes entre os tratamentos. Estes resultados são conseqüência da semelhança no GMD (Tabela 5) e do peso de abate, que foi o mesmo para todos os cordeiros.

As carcaças dos animais do tratamento PCA foram aproximadamente $1,2 \mathrm{~kg}$ mais pesadas que as dos animais do tratamento $\mathrm{CCF}$, o que deve ser

Tabela 5 - Valores médios do peso ao início do experimento (PIT), ganho médio diário (GMD), dias até o abate do cordeiro (DA), coeficiente de variação $(C V)$, valor de $F(F)$ e probabilidade $(P r>F)$ em pastagem de azevém (PCA), em confinamentos sem alimentação privativa (CON) e com alimentação privativa (CCF)

Table 5 - Average values weight at the beginning of the experiment (WBE), daily weight gain (DWG), days of the lamb in the experiment to achieve the slaughter weight (FI), coefficient of variation (CV), $F$ value and probability (Pr>F), in ryegrass pasture - RP, confinement - FNCP and confinement with creep-feeding - FCP

\begin{tabular}{|c|c|c|c|c|c|c|}
\hline \multirow{3}{*}{$\begin{array}{l}\text { Variável } \\
\text { Variable }\end{array}$} & \multicolumn{3}{|c|}{ Tratamento (Treatment) } & \multirow[b]{2}{*}{$\mathrm{CV}$} & \multirow[b]{2}{*}{$\mathrm{F}$} & \multirow[b]{2}{*}{$\operatorname{Pr}>\mathrm{F}$} \\
\hline & PCA & $\mathrm{CON}$ & CCF & & & \\
\hline & $R P$ & $F N C P$ & $F C P$ & $C V$ & $F$ & $\operatorname{Pr}>F$ \\
\hline $\begin{array}{l}\text { PIT }(\mathrm{kg}) \\
W B E(k g)\end{array}$ & 5,855 & 6,552 & 6,625 & 17,08 & 0,81 & 0,465 \\
\hline $\begin{array}{l}\operatorname{GMD}(\mathrm{kg}) \\
D W G(\mathrm{~kg})\end{array}$ & 0,317 & 0,332 & 0,285 & 15,71 & 1,89 & 0,184 \\
\hline $\begin{array}{l}\text { DA (dias) } \\
F I \text { (days) }\end{array}$ & 70 & 65 & 74 & 17,36 & 0,78 & 0,477 \\
\hline
\end{tabular}

Médias seguidas de letras distintas na linha diferem $(\mathrm{P}<0,05)$ entre si pelo teste Tukey.

Means followed by different letters in the row differ $(P<0.05)$ by Tukey test. 

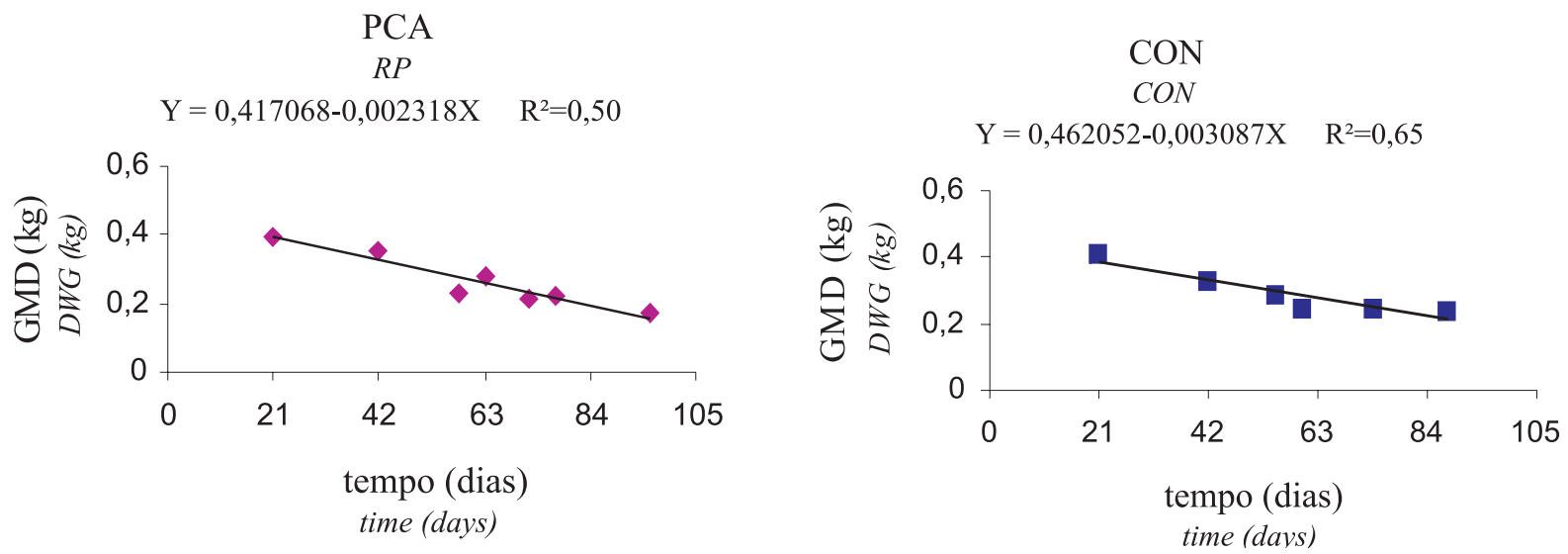

Figura 1 - Ganho médio diário $(\mathrm{kg})$ em relação ao tempo de experimento (dias), de cordeiros terminados em PCA pastagem cultivada de azevém; CON - confinamento sem alimentação privativa.

Figure 1 - Daily weight gain $(\mathrm{kg})$ in relation to the experiment time (days) of finished lambs in ryegrass pasture - RP and confinement - FNCP.

considerado, uma vez que, em um sistema de produção em que a forma de pagamento é por $\mathrm{kg}$ de carcaça, esta diferença pode trazer melhor remuneração ao ovinocultor que trabalha com pastagem de azevém.

Tonetto et al. (2004) obtiveram pesos de carcaça fria superiores aos deste experimento quando abateu cordeiros com peso vivo próximo a $31 \mathrm{~kg}-15,36$; 16,45 ; e $13,92 \mathrm{~kg}$, para pastagem natural com creep feeding, pastagem de azevém e confinamento com creep feeding, respectivamente.

O índice de quebra ao resfriamento foi semelhante entre os tratamentos. Os resultados, entretanto, não estão de acordo com Pires et al. (1999), que verificaram valores de 3,05\% para machos inteiros, $2,94 \%$ para machos castrados e $3,14 \%$ para fêmeas, sendo que os animais foram terminados em confinamento e abatidos aos 100 dias de idade. Neres et al. (2000) encontraram, em média, 2,96\% de índice de quebra ao resfriamento para os animais abatidos com 26 e $28 \mathrm{~kg}$ criados em sistema de creep feeding.

Não houve diferença para os valores de rendimentos de carcaças quente e de carcaça fria entre os tratamentos. Contudo, as carcaças dos cordeiros do tratamento PCA apresentaram rendimento de carcaça quente 3,02 e $8,75 \%$ superior às carcaças dos cordeiros CON e CCF, respectivamente.

Valores semelhantes foram verificados por Neres et al. (2001b), que trabalharam com o sistema de creep feeding, em pastagem de estrela branca (Cynodon plectostachyus), com cordeiros ao pé da mãe abatidos aos $28 \mathrm{~kg}$ e observaram rendimentos de carcaças quente e fria de 52,48 e $50,94 \%$, respectivamente.

Os valores médios, em cada tratamento, para comprimentos de carcaça e de perna, para compacidade, espessura de coxão, profundidade do peito, área de lombo, espessura de gordura, gordura de cobertura e marmoreio, estão apresentados na Tabela 7.

As variáveis compacidade, comprimento da carcaça e comprimento da perna não apresentaram diferenças significativas, em função da semelhança do peso das carcaças.

Garcia et al. (1999), ao avaliarem características de carcaças de cordeiros mestiços Texel confinados e alimentados com diferentes relações volumoso:concentrado em dietas isoprotéicas $(18 \%$ PB), obtiveram valores médios para comprimentos de carcaça e de perna de 51,4 e $33,6 \mathrm{~cm}$, respectivamente, semelhantes aos deste trabalho que foram, em média, para os três tratamentos, de 53,17 e $32,23 \mathrm{~cm}$, respectivamente.

Não houve diferença significativa para profundidade de peito entre os tratamentos PCA $(24,0 \mathrm{~cm})$ e CON $(24,0 \mathrm{~cm})$, mas foi significativa a diferença $(\mathrm{P}<0,05)$ entre estes tratamentos e o $\mathrm{CCF}(22,5 \mathrm{~cm})$. Embora não exista diferença entre tratamentos para pesos de carcaças quente e fria, as carcaças dos animais em PCA e CON foram, em média, $1 \mathrm{~kg}$ mais pesadas que as carcaças dos animais do CCF, o que Esta diferença poderia explicar a menor profundidade de peito da 
Tabela 6 - Valores médios, coeficiente de variação (CV), valor de $F(F)$ e probabilidade $(\mathrm{Pr}>\mathrm{F})$, dos pesos de carcaças quente (PCQ) e fria (PCF), do índice de quebra ao resfriamento (IQ), dos rendimentos carcaças quente (RCQ) e fria (RCF) de cordeiros em pastagem de azevém (PCA), confinamento sem alimentação privativa (CON) e confinamento com alimentação privativa (CCF)

Table 6 - Average values of hot carcass weight (HCW), cold carcass weight $(\mathrm{CCW})$, breakage index to cooling $(B I C)$, cold carcass yield (CCY), hot carcass yield $(H C Y)$, in ryegrass pasture - RP, confinement FNCP and confinement with creep-feeding - FCP, coefficient of variation (CV), $F$ value and probability (Pr>F)

\begin{tabular}{|c|c|c|c|c|c|c|}
\hline \multirow[b]{2}{*}{$\begin{array}{l}\text { Variável } \\
\text { Variable }\end{array}$} & \multicolumn{3}{|c|}{$\begin{array}{c}\text { Tratamento } \\
\text { Treatment } \\
\end{array}$} & \multirow[b]{2}{*}{$\mathrm{CV}$} & \multirow[b]{2}{*}{$\mathrm{F}$} & \multirow[b]{2}{*}{$\operatorname{Pr}>\mathrm{F}$} \\
\hline & $\begin{array}{c}\text { PCA } \\
R P\end{array}$ & $\begin{array}{c}\mathrm{CON} \\
F N C P\end{array}$ & $\begin{array}{l}\text { CCF } \\
F C P\end{array}$ & & & \\
\hline $\begin{array}{l}\mathrm{PCQ}(\mathrm{kg}) \\
H C W(\mathrm{~kg})\end{array}$ & 14,606 & 14,230 & 13,319 & 7,41 & 2,42 & 0,122 \\
\hline $\begin{array}{l}\mathrm{PCF}(\mathrm{kg}) \\
C C W(\mathrm{~kg})\end{array}$ & 14,220 & 13,852 & 13,000 & 7,34 & 2,32 & 0,132 \\
\hline $\begin{array}{l}\mathrm{IQ}(\%) \\
\text { BIC (\%) }\end{array}$ & 2,71 & 2,72 & 2,43 & 15,85 & 0,92 & 0,419 \\
\hline $\begin{array}{l}\mathrm{RCQ}(\%) \\
H C Y(\%)\end{array}$ & 52,76 & 51,22 & 48,52 & 5,94 & 3,04 & 0,078 \\
\hline $\begin{array}{l}\mathrm{RCF}(\%) \\
C C Y(\%)\end{array}$ & 51,37 & 49,86 & 47,36 & 5,83 & 2,95 & 0,083 \\
\hline
\end{tabular}

Médias seguidas de letras distintas na linha diferem $(P<0,05)$ entre si pelo teste Tukey.

Averages followed by different letters in the row differ $(P<.05)$ Tukey test.

carcaça dos animais do CCF. El Karin et al. (1988) demostraram que a medida da profundidade de peito é a que melhor se correlaciona com o peso de carcaça.

Avaliando as características das carcaças de cordeiros mestiços Texel, confinados por um período de 59 dias recebendo diferentes relações volumoso:concentrado em dietas isoprotéicas (18\% PB), Garcia et al. (1999) encontraram valor médio de profundidade de peito de $24,1 \mathrm{~cm}$, semelhante ao observado nos tratamentos PCA e CON.

A área de olho de lombo não diferiu entre tratamentos, apresentando valores de 12,$6 ; 14,4 ; 11,3 \mathrm{~cm}^{2}$, para PCA, CON e CCF, respectivamente. Tonetto et al. (2004) observaram, em cordeiros criados ao pé da mãe em pastagem natural com creep feeding, pastagem de azevém e confinamento com creep feeding e abatidos com peso médio de $31 \mathrm{~kg}$, área de olho de lombo de 14,$25 ; 14,28$ e $11,92 \mathrm{~cm}^{2}$, respectivamente.

As espessuras de coxão, de gordura, gordura de cobertura e o marmoreio foram semelhantes $(\mathrm{P}>0,05)$ entre os animais nos diferentes tratamentos.
Tabela 7 - Valores médios, coeficiente de variação (CV) valor de $F(F)$ e probabilidade $(\mathrm{Pr}>\mathrm{F})$ em cada tratamento, para comprimentos de carcaça (CC) e de perna (CP), compacidade (CM), espessura de coxão (EC), profundidade de peito (PRP), área de lombo $(\mathrm{Al})$, espessura de gordura (EG), gordura de cobertura (GC) e marmoreio (MAR)

Table 7 - Average values, coefficient of variation (CV), $F$ value $(F)$, and probability $(P r>F)$ in each treatment for carcass length (CL), leg length ( $L L)$, Compactiveness (CM) thigh thickness (TT), chest deepness (CD), loin area ( $L A)$, grease thickness (GT), cover grease (CG), marbling (MAR)

\begin{tabular}{|c|c|c|c|c|c|c|}
\hline \multirow[b]{2}{*}{$\begin{array}{l}\text { Variável } \\
\text { Variable }\end{array}$} & \multicolumn{3}{|c|}{$\begin{array}{c}\text { Tratamento } \\
\text { Treatment }\end{array}$} & \multirow[b]{2}{*}{$\mathrm{CV}$} & \multirow[b]{2}{*}{$\mathrm{F}$} & \multirow[b]{2}{*}{$\operatorname{Pr}>F$} \\
\hline & $\begin{array}{c}\text { PCA } \\
R P\end{array}$ & $\begin{array}{c}\mathrm{CON} \\
F N C P\end{array}$ & $\begin{array}{l}\text { CCF } \\
F C P\end{array}$ & & & \\
\hline $\begin{array}{l}\overline{C C}(\mathrm{~cm}) \\
C L(\mathrm{~cm})\end{array}$ & 53,1 & 52,9 & 53,5 & 1,61 & 0,64 & 0,542 \\
\hline $\begin{array}{l}\mathrm{CP}(\mathrm{cm}) \\
L L(\mathrm{~cm})\end{array}$ & 31,7 & 32,6 & 32,4 & 3,11 & 1,43 & 0,270 \\
\hline $\begin{array}{l}\mathrm{CM}(\mathrm{kg} / \mathrm{cm}) \\
C M(\mathrm{~kg} / \mathrm{cm})\end{array}$ & 0,267 & 0,261 & 0,243 & 7,21 & 2,83 & 0,090 \\
\hline $\begin{array}{l}\mathrm{EC}(\mathrm{cm}) \\
T T(\mathrm{~cm})\end{array}$ & 9,7 & 9,8 & 9,8 & 7,21 & 0,02 & 0,979 \\
\hline $\begin{array}{l}\mathrm{PRP}(\mathrm{cm}) \\
C D(\mathrm{~cm})\end{array}$ & $24,0^{\mathrm{a}}$ & $24,0^{\mathrm{a}}$ & $22,5^{\mathrm{b}}$ & 2,98 & 8,62 & 0,003 \\
\hline $\begin{array}{l}\mathrm{Al}\left(\mathrm{cm}^{2}\right) \\
L A\left(\mathrm{~cm}^{2}\right)\end{array}$ & 12,6 & 14,4 & 11,3 & 16,90 & 3,16 & 0,071 \\
\hline $\begin{array}{l}\mathrm{EG}(\mathrm{mm}) \\
G T(\mathrm{~mm})\end{array}$ & 2,8 & 1,3 & 1,6 & 52,27 & 3,60 & 0,052 \\
\hline $\begin{array}{l}\mathrm{GC}(1-5) \\
C G(1-5)\end{array}$ & 3,4 & 3,0 & 2,9 & 14,54 & 1,87 & 0,188 \\
\hline $\begin{array}{l}\operatorname{MAR}(\mathrm{mm}) \\
\operatorname{MAR}(1-5)\end{array}$ & 2,3 & 1,9 & 2,0 & 17,70 & 2,14 & 0,519 \\
\hline
\end{tabular}

Médias seguidas de letras distintas na linha diferem $(P<0,05)$ entre si pelo teste Tukey.

Means followed by different letters in the row differ $(P<.05)$ by Tukey test.

Macedo et al. (2000) citam que a gordura é o componente da carcaça que apresenta maior variação, sendo influenciada principalmente pelo sistema de terminação, pelo genótipo e pela razão idade/peso do animal, tornando-se fator fundamental, haja vista a aversão do consumidor moderno ao excesso de tecido adiposo. Por isso, devemos buscar produção de carne de cordeiro com pouca gordura de cobertura, uma vez que, em todos os tratamentos, não houve diferenças para esta variável.

Sents et al. (1982) afirmam que, à medida que a idade e o peso de abate dos animais avançam, elevase a espessura de gordura. Nesse contexto, os animais deste experimento não demonstraram diferença, 
uma vez que o ganho médio diário, a idade e o peso ao abate foram semelhantes. Sainz (1996) explica que o animal muito jovem ainda não teve a oportunidade de depositar gordura intramuscular, o que justifica os resultados obtidos.

\section{Conclusões}

Não há efeito dos sistemas de criação em pastagem cultivada de azevém, de confinamento ou de confinamento associado ao creep-feeding sobre o desempenho e as características da carcaça de cordeiros abatidos aos $28 \mathrm{~kg}$ de peso vivo.

Ovelhas com cria ao pé, confinadas, ganham peso durante a lactação.

\section{Literatura Citada}

ASSOCIATION OF ANALITIC CHEMIST - AOAC. Official methods of analysis. 14.ed. Washington, D.C.: 1984. 1141p.

BORGES, A.L.C.C.; GONÇALVES, L.C.; RODRIGUEZ, N.M. et al. Qualidade de silagens de híbridos de sorgo de porte alto com diferentes teores de tanino e umidade no colmo. Arquivo Brasileiro de Medicina Veterinária e Zootecnia, v.49, n.4, p.441-452, 1997.

BRASIL- MINISTÉRIO DA AGRICULTURA, Levantamento de Reconhecimento dos Solos do Estado do Rio Grande do Sul. Recife, Ministério da Agricultura, 1973. 430p. (Boletim Técnico).

BROWN, T.H. The early weaning of lambs. Journal of Agricultural Science, v.23, p.191-204, 1994.

CAMPBELL, A.G. Grazed pastures parameters: I. Pasture dry matter production and availability in a stocking rate and grazing management experiment with dairy cows. Journal of Agricultural Science, v.67, n.2, p.211-216, 1966.

CANTO, W.M.; MOOJEN, E.L.; CARVALHO, P.C.F. Produção de cordeiros em pastagem de azevém e trevo branco sob diferentes níveis de resíduos de forragem. Pesquisa Agropecuária Brasileira, v.34, n.2, p.309-316, 1999.

EL KARIN, A.I.A.; OWENS, J.B.; WHITAKER, C.J. Measurement on slaughter weight, side weight carcass joints and their association with composition of two types of sud desert sheep. Journal of Agriculture Science, v.110, p.65-69, 1988.

FARINATI, L.H.E. Crescimento e comportamento ingestivo de ovinos em pastagem de azevém (Lolium multiflorum Lam.) recebendo suplementação energética ou protéica. Santa Maria: Universidade Federal de Santa Maria, 2002. 108p. Dissertação (Mestrado em Zootecnia) - Universidade Federal de Santa Maria, 2002.

FIGUEIRÓ, P.R.P. Manejo alimentar do rebanho ovino. In: SIMPÓSIO PAULISTA DE OVINOCULTURA, 1., 1989, Campinas. Anais... Campinas: Fundação Cargil, 1989. p.22-33.

FREITAS, E.A.G.; DUFLOTH, J.H.; GREINER, L.C. Tabela de composição químico-bromatológica e energética dos alimentos para ruminantes em Santa Catarina. Florianópolis: EPAGRI, 1994. 333p. (Documentos, 155).

GARCIA, C.A.; SILVA SOBRINHO, A.G.; GASTALDI, K.A.
Influência das diferentes relações volumoso:concentrado e pesos de abate de cordeiros confinados. In: REUNIÃO ANUAL DA SOCIEDADE BRASILEIRA DE ZOOTECNIA, 36. 1999, São Paulo, Anais... São Paulo: Gnosis, 1999, CDROM. Qualidade de produtos de origem animal. QUA-018

GARDNER, A.L. Técnicas de pesquisa em pastagens e aplicabilidade de resultados em sistemas de produção. Brasília: IICA/EMBRAPA-CNPGL. 1986. 197p. (Série publicações Miscelâneas, 634).

GIBB, M.J.; TREACHER, T.T. The effect of herbage allowance on lambs grazing perennial ryegrass and red clover swards. Journal of Agricultural Science, v.86, p.355-365, 1976.

GIOTTO, E. Manual Siter 3.1. UFSM. CCR. Departamento de Engenharia Rural. 187p. 2001.

MACEDO, F.A.F.; SIQUEIRA, E.R.; MARTINS, E.N. et al. Qualidade de carcaça de cordeiros Corriedale, Bergamácia x Corriedale e Hampshire Dow x Corriedale terminados em pastagem e confinamento. Revista Brasileira de Zootecnia, v. 29, n.5, p.1520-1527, 2000.

MORENO, J.A. Clima do Rio Grande do Sul. Porto Alegre: Secretaria da Agricultura, 1961. 41p.

MÜLLER, L. Normas para avaliação de carcaças e concurso de carcaças de novilhos. Santa Maria: Universidade Federal de Viçosa, 1980. v.1, 31p.

MÜLLER, L.; PIRES, C.C.; TONETTO, C.J. et al. Desempenho de ovelhas com cria ao pé em diferentes sistemas de alimentação. In: REUNIÃO ANUAL DA SOCIEDADE BRASILEIRA DE ZOOTECNIA, 39., 2002, Recife. Anais... Recife: Sociedade Brasileira de Zootecnia CD-ROM.

MUNIZ, E.N.; PIRES, C.C.; SILVA, J.H.S. et al. Efeito do número de cordeiros por parto e do sexo do cordeiro no crescimento ponderal. In: REUNIÃO ANUAL DA SOCIEDADE BRASILEIRA DE ZOOTECNIA, 34., 1997, Juiz de Fora. Anais... Juiz de Fora: Sociedade Brasileira de Zootecnia, 1997. p.266-268.

NATIONAL RESEARCH COUNCIL - NRC. Nutrient requirements of sheep. 6.ed. Washington, D.C.: National Academy Press, 1985. 90p.

NATIONAL RESEARCH COUNCIL - NRC . Nutrient requirement of dairy cattle. 6.ed. Washington, D.C.: National Academy Press, 1989.

NERES, M.A.; GARCIA, C.A.; MONTEIRO, A.L.G. et al. Desempenho, peso e rendimento de carcaças de cordeiros criados em creep feeding. In: REUNIÃO ANUAL DA SOCIEDADE BRASILEIRA DE ZOOTECNIA, 37., 2000, Viçosa, MG. Anais... Viçosa, MG: Gnosis, 2000 Nutrição de Ruminantes. CD-ROM, NUTR-021.

NERES, M.A.; GARCIA, C.A.; MONTEIRO, A.L.G. et al. Níveis de feno de alfafa (Medicago Sativa l.) e forma física da ração no desempenho de cordeiros em creep feeding. Revista Brasileira de Zootecnia, v.30, n.3, p.941-947, 2001a. (Suplemento 1)

NERES, M.A.; MONTEIRO, A.L.G.; GARCIA, C.A. et al. Forma física da ração e pesos de abate nas características de carcaça de cordeiros em creep feeding. Revista Brasileira de Zootecnia, v.30, n.3, p.948-954, 2001b (suplemento 1).

NEUMANN, M.; RESTLE, J.; ALVES FILHO, D.C. et al. Avaliação de diferentes hibridos de sorgo quanto aos componentes da planta e silagem produzida. Revista Brasileira de Zootecnia, v.31, n.1, p.302-312, 2002 (suplemento).

OSÓRIO, J.C.S.; OSÓRIO, M.T.; JARDIM P.O.C. Métodos para avaliação da produção ovina in vivo na carcaça e na carne. Pelotas: Universidade Federal de Pelotas, 1998. 107p. 
PIRES, C.C.; CARVALHO, S.; GRANDI, A. et al. Características quantitativas e composição tecidual da carcaça de cordeiros terminados em confinamento. Ciência Rural, v.29, n.3. p.539-543. 1999.

SAINZ. R.D. Qualidade das carcaças e da carne ovina e caprina In: REUNIÃO ANUAL DA SOCIEDADE BRASILEIRA DE ZOOTECNIA, 33., 1996, Fortaleza. Anais... Fortaleza: Sociedade Brasileira de Zootecnia,1996. p.7.

STATISTICAL ANALYSES SYSTEM - SAS. User's guide: statistics. version 6.8 Cary: 1993, 956p.

SENTS, A.E.; WALTERS, L.E.; WHITEMAN, J.V. Performance and carcass characteristics of ram lambs slaughtered at different weights. Journal of Animal Science, v.55, n.6, p.13601368, 1982.

SIQUEIRA, E.R.; AMARANTE, A.F.T.; FERNANDES, S. Estudo comparativo da recria de cordeiros em confinamento e pastagem. Veterinária e Zootecnia, v.5, p.17-28, 1993.

SILVA SOBRINHO, A.G. Aspectos quantitativos e qualitativos da produção de carne ovina. A produção animal na visão dos Brasileiros. Piracicaba: Fundação de Estudos Agrários "Luiz de Queiroz", 2001. p.425-446.
TONETTO, C.J.; PIRES, C.C.; MULLER, L. et al. Ganho de peso e características da carcaça de cordeiros terminados em pastagem natural suplementada, pastagem cultivada de azevém (Lolium multiflorum Lam.) e confinamento. Revista Brasileira de Zootecnia, v.33, n.1, p.225-233, 2004.

TILLEY, J.M.; TERRY, R.A. A two-stage technique for the in vitro digestion of forage crops. Journal British Grassland Society, v.18, p.104-111, 1963.

Recebido em: 16/12/03

Aceito em: 06/04/05 